\title{
O Decálogo do Deuteronômio em comparação com o do Êxodo
}

\author{
The Decalogue of Deuteronomy compared
}

to that of Exodus

VALMOR DA SILVA ${ }^{a}$

\section{Resumo}

Analisa os acréscimos e modificações principais introduzidos no contexto e no texto do decálogo, pela versão do Deuteronômio (Dt 5,6-21), em comparação com a do Êxodo (Ex 20,2-17). As principais mudanças que cercam os textos do decálogo, com relação ao contexto, referem-se ao lugar geográfico, aos personagens que transmitem os mandamentos, ao contexto literário e às motivações teológicas. Além disso, discutem-se as mudanças relativas a três preceitos específicos. A guarda do sábado, no Deuteronômio, é justificada pela memória da libertação da casa da escravidão do Egito, diferente do Êxodo, que apelava para o descanso divino no sétimo dia da criação. O mandamento que ordena honrar pai e mãe, no Deuteronômio é acompanhado da promessa, "e tudo corra bem para ti". O último mandamento, no Deuteronômio, distingue dois verbos, não cobiçarás a mulher do próximo e não desejarás os bens, com o acréscimo "nem o seu campo". Através do método da comparação sinótica entre os dois relatos, o estudo objetiva destacar as mudanças e apresentar suas possíveis explicações.

Palavras-chave: Decálogo. Mandamentos. Sábado. Honrar pai e mãe.

\section{Abstract}

It analyzes the major additions and modifications introduced in the context and in the text of the Decalogue by the version of Deuteronomy (Dt 5,6-21) compared to that of the Exodus (Ex

\footnotetext{
a Pontifícia Universidade de Goiás (PUC Goiás), Goiânia, GO, Brasil. Doutor em Ciências da Religião, e-mail: lesil@terra.com.br
} 
20,2-17). The main changes surrounding the texts of the decalogue, in relation to the context, refer to the geographical place, the characters who transmit the commandments, the literary context and the theological motivations. In addition, changes regarding three specific precepts are discussed. Sabbath keeping in Deuteronomy is justified by the memory of the deliverance from Egypt's house of slavery, unlike the Exodus, which called for divine rest on the seventh day of creation. The commandment to honor father and mother in Deuteronomy is accompanied by the promise, "Let it go well for you." The last commandment in Deuteronomy distinguishes two verbs, you shall not covet the neighbor's wife, and you shall not desire the goods, with the addition "neither her field." Through the synoptic comparison method between the two reports, the study aims to highlight the changes and present their possible explanations.

Keywords: Decalogue. Commandments. Saturday. Honor mother and father.

\section{Introdução}

O decálogo é talvez o texto mais conhecido e mais citado das escrituras hebraicas, o mais importante para as Igrejas Cristãs e o mais influente sobre a civilização ocidental, para fazer coro às afirmações de Gerstenberger (1996, p. 8). Por isso mesmo, é um dos textos mais estudados de toda a Bíblia. O presente artigo propõe um diálogo com a pesquisa, para apresentar, de maneira didática, acréscimos e modificações feitos pelo texto do decálogo de Dt 5,6-21, em comparação com o de Ex 20,2-17. ${ }^{1}$

Os dois textos do decálogo são fundamentalmente idênticos, com os mesmos mandamentos, seguindo a mesma ordem, mas apresentam diferenças que resultam muito significativas. Loza (1989, p. 100-102) conta uma lista de vinte e duas diferenças, que vão desde o acréscimo de um "e" (waw hebraico) até as motivações em preceitos como a guarda do sábado, a honra aos pais e o

\footnotetext{
1 A literatura sobre o decálogo é vasta, como anota Gerstenberger (1996, p. 9, nota 4), que recomenda as referências de Hossfeld (1982) e Levin (1985). Na impossibilidade de uma abrangência maior, no espaço de um artigo, privilegiam-se aqui, na medida do possível, obras em língua portuguesa.
} 
desejo do campo do próximo. As diferenças, em geral, se referem a acréscimos do texto de Deuteronômio em comparação àquele do Êxodo. "De fato Ex 20,2-17 contém 172 palavras e Dt 5,6-21 consta de 189" (LOZA, 1989, p. 102). ${ }^{2}$

Nas tradições das igrejas, popularizou-se o nome "dez mandamentos", mas as denominações bíblicas não enfatizam esse enfoque. Encontra-se, na Bíblia, o termo "palavras", com inúmeras referências, "duas tábuas", também amplamente atestado, ou "dez palavras" (Ex 34,28; Dt 4,13; 10,4). Essa última denominação foi traduzida para o grego como "decálogo", e se impôs na história, de modo que será empregada, preferencialmente, neste estudo. ${ }^{3}$

Há igualmente uma longa discussão histórica sobre a numeração dos mandamentos, de um a dez, ou até doze. Diferentes numerações são seguidas pelos judeus e pelos cristãos em suas variadas denominações, a partir de Agostinho. Após a Reforma, a tradição protestante divide o primeiro mandamento dos católicos em dois, enquanto a tradição católica divide em dois o último mandamento dos protestantes. O presente artigo evita essa discussão e nomeia os três preceitos analisados pelo seu conteúdo, isto é, sábado, honrar pai e mãe e cobiça aos bens do próximo. ${ }^{4}$

O estudo passa a analisar esses três mandamentos, por suas variantes na versão do Deuteronômio. Antes, porém, compara o contexto dos dois decálogos, que possui variações maiores numa e noutra lista.

\section{Duas montanhas: Sinai e Horeb}

O decálogo está ambientado, geograficamente, em torno a uma montanha, conhecida como Sinai ou como Horeb. Nessa montanha, foi firmada

\footnotetext{
2 A partir desses dados, abre-se longa discussão sobre a história dos dois decálogos. A propósito, pode-se consultar Crüsemann (1995, p. 15-24). Meynet (2000, p. 659, nota 3) sintetiza: "A exegese moderna atribui geralmente a versão do Êxodo à escola sacerdotal, e a do Dt à escola deuteronomista; a primeira seria a mais antiga".

3 Entre numerosas discussões sobre a terminologia, pode-se consultar Garcia Lopez (1995, p. 22-23); Gerstenberger (1996, p. 10-11); Carrière (2005, p. 91-94).

${ }^{4}$ Dntre muitas explicações, pode-se consultar a tabela comparativa em Harrelson (1987, p. 71); e em Serafini (2018, p. 16-18); os dados históricos em Oliveira (1987, p. 11).
} 
a aliança entre Deus e o seu povo. Ali, Deus entregou os diversos códigos de leis. Ela se conserva como o lugar da teofania, isto é, onde Deus se manifesta e torna conhecida a sua vontade.

A localização geográfica dessa montanha não é identificada, embora se mantenha uma longa tradição em torno ao djebel Musa, ao sul da península do Sinai (Bíblia de Jerusalém, 2002, nota b a Ex 19,2). Tampouco são identificados, Sinai e Horeb, como duas montanhas ou dois nomes para mesma montanha. No Êxodo, predomina o nome do Sinai: Ex 19,1-2.11.18.20.23; 24,16; 31,18; 34,2.4.29.32. No Deuteronômio predomina o nome do Horeb: Dt 1,2.6.19; 4,10.15; 5,2; 9,8; 18,$16 ; 28,69$. Noutras passagens, cita-se a montanha, sem precisão, mas o contexto pode indicar tratar-se do Sinai: Ex 19,2.3.12-14.16-18.20.23; 20,18; 24,4.12.13.15.17.18; ou do Horeb: Dt 5,4-5.22; 9,9-10.15; 10,4.10). (GARCIA LOPEZ, 1995, p. 12-13).

Igualmente o contexto geográfico e cronológico mais amplo tem diferenças. Segundo o Êxodo, o primeiro decálogo é revelado após a travessia do mar Vermelho, numa grande teofania, no deserto do Sinai (Ex 19,16-25). Já no Deuteronômio, a revelação acontece após a travessia do rio Jordão, nas planícies de Moab (Dt 4,44-49). Além disso, o decálogo do Deuteronômio é proclamado quarenta anos mais tarde, sob a autoridade de Moisés (MEYNET, 2000, p. 684).

\section{Dois locutores: Deus e Moisés}

Embora todas as leis sejam apresentadas como palavra de Deus, no primeiro decálogo, a motivação é introduzida com dois verbos e dois sujeitos diferentes: "Desceu, pois, Moisés até o povo, e lhe disse..." (Ex 19,25); a frase ficou truncada, e a sequência retoma outro sujeito e outro verbo: "Deus pronunciou todas estas palavras, dizendo..." (Ex 20,1). As palavras do decálogo, portanto, são pronunciadas diretamente por Deus. No segundo decálogo, diferentemente, as palavras são colocadas na boca de Moisés. "Moisés convocou todo o povo e disse...” (Dt 5,1); “Eu (Moisés) estava entre Yhwh e vós, 
para vos anunciar a palavra de Yhwh, pois ficastes com medo do fogo e não subistes à montanha. Ele (Yhwh) disse..." (Dt 5,5). ${ }^{5}$

Aqui, portanto, Moisés pronuncia as palavras citando o ditado de Deus para transmiti-las ao povo. Esse dado confirma, naturalmente, um escopo teológico. "De fato, tudo se passa como se os narradores do Êxodo e do Deuteronômio deixassem subentender que o decálogo é uma palavra divina e humana inseparavelmente, pois ela jorra de um encontro, de uma aliança entre Moisés e Deus na presença do povo (ver Ex 19,9.19)" (WÉNIN, 1997, p. 16).

Wénin (1997, p. 15-16) anota ainda que os textos hesitam quanto ao dedo que escreveu os mandamentos sobre as tábuas de pedra que contêm o decálogo, segundo o Deuteronômio. Enquanto são unânimes em afirmar que a primeira edição das tábuas é do dedo de Deus (Ex 31,18; 32,16 e Dt 10,1-2), a mesma unanimidade não é observada quanto à segunda edição, em que Moisés escreve as dez palavras (Ex 34,27-28), mas Deus anuncia que ele mesmo o fará (Ex 34,1) e efetivamente o realiza (Dt 10,2-4).

O fato curioso, nesse contexto, é que Moisés modifica o decálogo, segundo a versão do Deuteronômio, como será demonstrado adiante, neste estudo. Moisés, portanto, é apresentado com autoridade para convocar o povo, para proclamar a lei, para exigir o cumprimento da lei e para introduzir modificações no código legal. E o faz com liberdade, especialmente no preceito do sábado, como será apresentado adiante (MARKL, 2017, p. 23-24).

\section{Dois códigos: Aliança e Deuteronômio}

O texto do decálogo se insere em dois contextos literários significativos em todo o Pentateuco e, particularmente, nos livros do Êxodo e do Deuteronômio. Em ambos, o decálogo abre códigos legislativos. No Êxodo, ele

\footnotetext{
${ }^{5}$ Segue-se, normalmente, a tradução da Bíblia de Jerusalém (2002), com eventuais adequações ao texto original hebraico. Quanto ao nome divino, adota-se o tetragrama original Yhwh, dito Adonay, Javé, Jeová ou Senhor.
} 
está no início do código da aliança, e no Deuteronômio, ele encabeça o discurso de Moisés que prepara o código legal deuteronômico (MARKL, 2017, p. 23). ${ }^{6}$

Em ambas as versões do decálogo, estão entrelaçados contextos teológicos mais amplos e centrais do Pentateuco, sobretudo através do mandamento do sábado. Em Êxodo, o mandamento remete à criação, em Deuteronômio à libertação. Criação e libertação constituem um paradigma para a comunidade, com diferentes acentos, conforme o contexto do decálogo no Pentateuco (MARKL, 2017, p. 23, nota 25; KLINGBEIL, 2010, p. 491-509).

Entretanto, o texto do decálogo, tanto num contexto quanto noutro, literariamente não tem conexão com o contexto imediato. No Êxodo, o decálogo interrompe a narrativa da teofania, em meio à qual está inserido. Não tem ligação com o versículo que o precede $($ Ex 19,25) nem com o que segue $(20,18)$, demonstrando que a descrição da narrativa ficaria mais lógica sem o decálogo. Já no Deuteronômio, a conexão é maior, mas não totalmente lógica. $A$ apresentação que antecede o decálogo (Dt 5,1-4) bem como a que o sucede $(5,22)$ dirige-se à assembleia, no plural "vós", enquanto o texto do decálogo (5,6-21) é pronunciado em singular "tu” (GARCIA LOPEZ, 1995, p. 11).

Desses e outros dados, os estudos deduzem que os textos do decálogo formavam unidade independente, só mais tarde inserida no atual contexto do Pentateuco. Sua inserção teria sido posterior, obra de um ou diversos redatores. ${ }^{7}$

\section{Dois contextos históricos: o ontem do Êxodo e o hoje da Aliança}

\footnotetext{
6 São três os códigos legislativos do Pentateuco: código da aliança (Ex 20,22-23,19), código deuteronômico (Dt 12-26), código de santidade (Lv 17-26). Para discussão, ver Bíblia de Jerusalém (2002, p. 22-27), e nota, na mesma Bíblia, precedente ao início de cada código (Ex 20,22; Dt 12,1 e Lv 17,1).

7 Para discussão sobre a história da redação do decálogo, pode-se consultar García López (1977, p. 481-522); Crüsemann (1995, p. 25-31); Schmidt (1996, p. 45-56). Para uma abordagem históricocrítica sobre os mandamentos na sociedade tribal, na tributária e na capitalista, confira Silva (1986, p. 38-51).
} 
Os dois decálogos são precedidos por uma palavra de Deus relativa à memória da libertação do Êxodo, que diz: "Eu sou Yhwh teu Deus, que te fez sair da terra do Egito, da casa da escravidão" (Ex 20,2; Dt 5,6).

A propósito dessa apresentação do autor das palavras, Wénin (1997, p. 12) afirma: "Basicamente, se pode dizer que as dez palavras indicam a Israel como não retornar mais ao Egito e se engajar numa aliança com este Deus que Ihe dá liberdade e vida". Com sua linguagem metafórica popular, Mesters (1986, p. 20) expressa a mesma convicção: “Os Dez Mandamentos são como um grande quadro pendurado na parede da vida. O prego que o sustenta é a afirmação de Deus que diz: 'Eu sou Javé, teu Deus, que te fez sair da terra do Egito, da casa da escravidão!". A propósito deste modo "estranho" de iniciar os mandamentos, Siqueira (2015, p. 203) reitera: “Javé não se apresenta como um rei legislador ou um juiz do Supremo Tribunal, mas como aquele que libertou os destinatários da casa da servidão".

O decálogo é ambientado, portanto, no contexto histórico do evento do êxodo, após libertar os hebreus "da casa da escravidão", com a saída do Egito e a passagem do mar Vermelho, em vista da libertação na terra de Canaã. Essas leis, assim como toda a legislação do Pentateuco e os episódios históricos que as emolduram, visam assegurar a libertação definitiva do povo, rumo à nova sociedade. O Êxodo permanece, na memória bíblica, como o evento fundante da nação, o exemplo para cada momento histórico em que a luta pela libertação se faz necessária. ${ }^{8}$

Liberto da escravidão do Egito, Israel adere à lei e entra na aliança que Deus the propõe. Libertação, lei e aliança constituem um tripé inseparável que sustenta a história do Israel bíblico. No êxodo nasce Israel livre, logo, acolhe

\footnotetext{
8 Os comentários relativos ao evento êxodo, assim como os demais textos bíblicos, possuem intenção teológica e não de reportagens históricas. Para uma discussão sobre o momento histórico em que o decálogo assumiu a sua forma atual, no ambiente profético do século VIII a.C. pode-se consultar Crüsemann (1995, p. 28); e também Reimer; Reimer (1999, p. 44-45).
} 
a lei para assegurar essa liberdade e aceita a aliança como proposta de felicidade na nova terra. ${ }^{9}$

Essa realidade está explícita no contexto do Êxodo, antes e depois do decálogo: "Agora, se ouvirdes a minha voz e guardardes a minha aliança, sereis para mim uma propriedade peculiar entre todos os povos, porque toda a terra é minha" (Ex 19,5; cf. 24,8). Já no contexto do Deuteronômio, a aliança antiga, do Êxodo, é atualizada para o hoje de uma nova geração: "Ouve, ó Israel, os estatutos e as normas que hoje proclamo aos vossos ouvidos... Yhwh não concluiu esta Aliança com nossos pais, mas conosco, conosco que estamos hoje aqui, todos vivos" (Dt 5,1.3). Este hoje possui um sentido teológico profundo, que vai muito além da cronologia histórica. Com efeito, a frase "conosco, conosco que estamos hoje aqui, todos vivos" (Dt 5,3), do ponto de vista narrativo, é anacrônica, pois uma é a geração que partiu do Egito, outra, a que entrou na terra prometida, segundo o relato (SERAFINI, 2018, p. 124). A intenção do texto, contudo, vai além. Trata-se de um hoje efetivo, cotidiano, que se renova a cada geração.

Logo adiante, o Deuteronômio apresenta a profissão de fé familiar, conhecida como credo histórico (Dt 6,20-23), em que o hoje da aliança é projetado para todo tempo, para "amanhã, quando o teu filho te perguntar". A pergunta se refere ao sentido dos "testemunhos e estatutos e normas", e a resposta aviva a memória de que "éramos escravos do Faraó no Egito, mas Yhwh nos fez sair do Egito com mão forte", e ainda "fez-nos sair de lá para nos introduzir e nos dar a terra"; "ordenou-nos então cumprirmos todos estes estatutos, temendo Yhwh nosso Deus, para que tudo nos corra bem, todos os dias; para dar-nos a vida, como hoje se vê". O evento do êxodo, com suas diversas tradições, permanece como um fio condutor que percorre toda a Bíblia

\footnotetext{
${ }^{9}$ Wénin (1997, p. 16-17) analisa o decálogo do Êxodo como palavra saída de uma aliança e palavra em vista da aliança. Carrière (2005, p. 91.98-100) vai mais longe e apresenta o decálogo não como uma lista de mandamentos, mas como uma "estrutura da aliança", em vista de uma "carta de direito".
} 
e é renovado inúmeras vezes, na lei, nos profetas, nos sapienciais e em todo o Novo Testamento (SILVA, 2004, p. 81-97)..$^{10}$

\section{Duas motivações para o sábado: criação e libertação (Dt 5,12-15)}

O mandamento relativo ao sábado é o mais extenso nas duas versões e o que foi mais ampliado com explicações e acréscimos. Isso confirma a importância que o descanso sabático foi adquirindo ao longo da história, principalmente na época do pós-exílio. Esse mandamento ocupa lugar central no decálogo, também como divisor entre os preceitos anteriores, relacionados a Deus, e aqueles que seguem, para regular os relacionamentos humanos. Com o preceito seguinte, de honrar pai e mãe, constituem os dois únicos mandamentos formulados de maneira positiva, diferente dos demais, com a partícula negativa "não" (CRÜSEMANN, 1995, p. 46)."1

Os acréscimos não querem dar explicações históricas, mas teológicas. Historicamente, o descanso sabático é muito antigo, anterior ao próprio decálogo, sendo atestado noutras legislações extra bíblicas e nos profetas antigos, como Os 2,13 e Am 8,5. As explicações teológicas, portanto, são posteriores, e revelam preocupações dos tempos pós exílicos (SCHMIDT, 1996, p. 124-125).

Segue o quadro comparativo entre as duas versões, para evidenciar as mudanças (grifadas em negrito), e os acréscimos (em caixa alta), na versão do Deuteronômio. $^{12}$

\footnotetext{
10 O decálogo tem repercussões em toda a Bíblia, seja com textos semelhantes, como Ex 34,14-26 e Dt 27,15-26), seja na releitura de leis, profetas e sapienciais, sem esquecer o Novo Testamento. Para discussão, veja Harrelson (1987, p. 55-62); Beauchamp (2000, p. 44-56).

11 Para um estudo sobre as estruturas dos dois textos do decálogo, pode-se consultar Meynet (2000, p. 659-692).

12 Dentre diversos estudos que apresentam uma sinopse das duas versões do decálogo, pode-se mencionar Garcia Lopez (1995, p. 44-45); Markl (2017, p. 26-27); Serafini (2018, p. 21-22).
} 


\begin{tabular}{|c|c|}
\hline Ex 20 & Dt 5 \\
\hline $\begin{array}{l}\text { ¿Lembra-te do dia do sábado para } \\
\text { santificá-lo. }\end{array}$ & $\begin{array}{l}\text { 12Guarda o dia de sábado para } \\
\text { santificá-lo, } \\
\text { CONFORME ORDENOU YHWH TEU }\end{array}$ \\
\hline${ }^{9}$ Trabalharás durante seis dias e farás & DEUS. \\
\hline toda a tua obra. & ${ }^{13}$ Trabalharás durante seis dias e farás \\
\hline${ }^{10} \mathrm{O}$ sétimo dia, porém, é o sábado de & toda a tua obra; \\
\hline Yhwh teu Deus. & ${ }^{14} \mathrm{O}$ sétimo dia, porém, é o sábado de \\
\hline Não farás nenhum trabalho, nem tu, & Yhwh teu Deus. \\
\hline nem teu filho, nem tua filha, nem teu & Não farás nenhum trabalho, nem tu, \\
\hline escravo, nem tua escrava, & $\begin{array}{l}\text { nem teu filho, nem tua filha, nem teu } \\
\text { escravo, nem tua escrava, }\end{array}$ \\
\hline $\begin{array}{l}\text { nem teu animal, } \\
\text { nem o estrangeiro que está em tuas }\end{array}$ & $\begin{array}{l}\text { NEM TEU BOI, NEM TEU JUMENTO, } \\
\text { nem QUALQUER dos teus animais, }\end{array}$ \\
\hline portas. & $\begin{array}{l}\text { nem o estrangeiro que está em tuas } \\
\text { portas. DESTE MODO O TEU ESCRAVO E } \\
\text { A TUA ESCRAVA PODERÃO REPOUSAR } \\
\text { COMO TU. }\end{array}$ \\
\hline${ }^{11}$ Porque em seis dias Yhwh fez o céu, a & ${ }^{15}$ Recorda que foste escravo na terra \\
\hline
\end{tabular}




\begin{tabular}{|l|l|}
\hline $\begin{array}{l}\text { terra, o mar e tudo o que eles contêm, } \\
\text { mas repousou no sétimo dia; }\end{array}$ & $\begin{array}{l}\text { do Egito, e que Yhwh teu Deus te fez } \\
\text { por isso Yhwh abençoou o dia do de lá com mão forte e braço } \\
\text { sábado e o consagrou. }\end{array}$ \\
& estendido. \\
& É por isso que Yhwh TEU DEUS TE \\
& ORDEU guardar o dia de sábado. \\
\hline
\end{tabular}

"Guarda o dia de sábado para santificá-lo" (Dt 5,12) é a primeira modificação ao preceito. Enquanto em Ex 20,8 o imperativo é do verbo "lembrar" (zkr), no paralelo correspondente, em Dt 5,12 encontra-se o verbo "guardar" (shmr). A recomendação para "guardar" de Deuteronômio parece mais precisa para a observância dos mandamentos e seu uso é mais frequente na literatura sob influência deuteronômica. Zkr seria mais litúrgico, tardio, talvez sacerdotal, em consonância com a motivação do sábado pelo descanso e consagração divina em Ex 20,11. O mesmo "lembra" (zkr) que introduziu o mandamento em Êxodo, passa a motivá-lo em Dt 5,15. No versículo onde as duas versões seguem redações diferentes, o Deuteronômio traz à lembrança a memória da libertação do êxodo, evento passado, para motivar o presente. Assim como Israel foi libertado da opressão do Egito pela mão do Senhor, assim agora, não pode impor a servidão a outras pessoas, e nem mesmo sobre os animais (Dt 5,14) (LOZA, 1989, p. 105-108).

“CONFORME ORDENOU YHWH TEU DEUS" (Dt 5,12) é um acréscimo que soa como refrão no decálogo de Deuteronômio, com três repetições, todas sem menção nos paralelos das palavras do Êxodo. Esse apelo à ordem do Senhor é acrescentado aqui, após a ordem de "guardar" o sábado (Dt 5,12); confirmado repetidamente ao final da motivação do mesmo preceito sabático (Dt 5,15); e reafirmado após o mandamento "honra teu pai e tua mãe" (Dt 5,16). 
Essa tríplice repetição reforça a relação entre os dois mandamentos, do sábado e da honra a pai e mãe, além da referência à terra, comum entre os dois (Dt 5,15.16). "É como se este duplo mandamento central fosse, de qualquer modo, a síntese, a quintessência do decálogo, e, portanto, de toda a lei" (MEYNET, 2000, p. 689-691).

Embora a ideia do ordenamento divino seja frequente na Bíblia, a expressão tal e qual não é comum. Dessa maneira precisa, ela se encontra em Dt 20,17d e 1Rs 13,21. Já a “fórmula de promulgação" ou "fórmula de citação" em primeira pessoa, na boca do Senhor "como eu te/vos prescrevo" pode ser contada mais de trinta vezes só no Deuteronômio (LOZA, 1989, p. 120). No contexto do Deuteronômio, portanto, a "fórmula de citação" estaria remetendo a um texto anterior, como mandamento já citado, não propriamente a uma situação concreta do momento. Loza (1989, p. 121) conclui que essas citações foram acrescentadas tardiamente, e que não comprovam o caráter deuteronômico do Decálogo. ${ }^{13}$

“NEM TEU BOI, NEM TEU JUMENTO, nem QUALQUER dos teus animais" (Dt 5,14$)$ é outra adição significativa, porque, além de recomendar o completo repouso sabático, demonstra particular sensibilidade para com os animais. Conecta, ademais, com o final do decálogo em Dt 5,21 (MAYES, 1980, p. 75). "A lei objetiva colocar um freio à exploração da força de trabalho no ritmo agrícola de Israel” (REIMER; REIMER, 1999, p. 41). A lei pressupõe, naturalmente, atividades agrícolas, com famílias constituídas segundo o modelo da "casa" patriarcal, incluindo força de trabalho com animais e escravos. Esse dado evidencia um acréscimo posterior ou um ordenamento tardio, visto que não pressupõe, naturalmente, o ambiente do deserto no qual os mandamentos são ambientados.

“DESTE MODO O TEU ESCRAVO E A TUA ESCRAVA PODERÃO REPOUSAR COMO TU" (Dt 5,14) é outro acréscimo que reforça a insistência sobre a

\footnotetext{
${ }^{13}$ Loza discute principalmente com Hossfeld (1982), que tende a atribuir os textos do decálogo, em geral, à redação deuteronômica.
} 
experiência da libertação, a partir da saída "da casa da escravidão". O preceito do repouso sabático estabelece a igualdade básica das pessoas, seja de classe social (escravos e estrangeiros), de gênero (filho e filha, escravo e escrava), e de espécie (animais domésticos) (NELSON, 2002, p. 83). ${ }^{14}$ Trata-se, portanto, de nova proposta de relacionamento, baseado justamente na experiência libertária do êxodo e em toda a teologia desenvolvida a partir desse evento. Nessa perspectiva, o Egito representa o modelo da sociedade da qual Deus fez Israel "sair", verbo repetido quase como refrão no próprio Deuteronômio, e modelo do lugar sobre o qual Deus declara: "Nunca mais voltareis por este caminho" (Dt 17,16), sob pena de "voltar ao Egito", e então "lá vos poreis à venda aos vossos inimigos como escravos e escravas, e não haverá comprador!” (Dt 28,68). O descanso sabático constitui um espelho da igualdade almejada, quando pessoas e animais, indistintamente, podem guardar um dia para se alegrar. O sábado significa, nesse contexto de êxodo, uma experiência de igualdade universal.

"Recorda que foste escravo na terra do Egito, e que Yhwh teu Deus te fez sair de lá com mão forte e braço estendido. É por isso que Yhwh teu Deus te ordenou guardar o dia de sábado" (Dt 5,15) é a principal modificação em todo o texto do decálogo. A referência ao Êxodo, "o evento criativo fundamental da história de Israel", foi introduzida para conectar com o início do decálogo em Dt 5,6 (MAYES, 1980, p. 75). O imperativo "recorda" reassume o zkr do início do decálogo em Ex 20,8, e o "escravo" ("ebed) é retomado do final da frase anterior, para trazer para o hoje do texto a insistência na libertação da escravidão.

Aqui o preceito do sábado se fundamenta em duas justificativas teológicas distintas. Enquanto o Êxodo justifica o sábado com o relato da

\footnotetext{
${ }^{14}$ Porém toma-se aqui a afirmação exatamente ao contrário do que diz o autor, conforme grifamos: "However, Sabbath means that the division between work and leisure is not to be a matter of social class (slave, alien), gender (son or daughter, male or female slave), or even species (domestic animals), but an opportunity for leisure provided to all" (o autor faz referência, em nota, a um artigo de Miller).
} 
criação, pelo repouso divino, no sétimo dia, a servir de modelo para o comportamento humano, o Deuteronômio apela para a experiência histórica da libertação do Egito, quando Deus mesmo libertou o povo da escravidão. A teologia da criação, de Êxodo, seria da época exílica, da mão sacerdotal, baseada na tradição já existente sobre a prática do sábado. A teologia do êxodo, de Deuteronômio, apela para a experiência do êxodo como "memória subversiva" para o povo bíblico (REIMER; REIMER, 1999, p. 44). Não havendo uma prescrição litúrgica explícita para qualquer prática religiosa no sábado, ambas as versões acentuam o caráter social desse dia de repouso total. Mas, de acordo com Siqueira (2015, p. 109) a versão do Deuteronômio amplia a dimensão social, com o acento na libertação do escravo como um padrão de comportamento para a sociedade. Klingbeil (2010, p. 500) afirma que as duas motivações são complementares e refletem situações históricas diversas, pois "a criação está subjacente à libertação, incluindo também o estrangeiro, porque toda a humanidade foi criada à imagem de Deus". Blevins (2016, p. 486) destaca que a teologia da libertação, do Êxodo, conectada com a revelação de Deus na história tem mais impacto pessoal e emocional e conclui que "a justificativa teológica dada pelo mandamento sabático em Deuteronômio 5 é mais forte que aquela dada em Êxodo 20", porque "move o destinatário do mandamento a considerar a sua solidariedade com outros - incluindo outros que ele não pode instintivamente considerar como seus iguais".

O mandamento do sábado possui uma história longa e complexa, tanto nos textos do Antigo quanto nos do Novo Testamento, com extensão para toda a trajetória posterior do Cristianismo e mesmo da humanidade em geral. Trata-se de um preceito religioso e, em muitas nações, de uma norma jurídica, transferido para o domingo, pela prática cristã fundamentada na ressurreição de Jesus. ${ }^{15}$

\footnotetext{
15 Para os aspectos históricos da redação e da recepção do mandamento do sábado, pode-se consultar Crüsemann (1995, p. 46-50).
} 


\section{Duas motivações para honrar pai e mãe: ordem e promessa (Dt 5,16)}

O preceito do honrar pai e mãe, ao lado do sábado, ocupam lugar central no decálogo, sendo os dois únicos formulados de maneira positiva. Este, da honra aos genitores, ademais, estabelece a passagem entre os mandamentos referentes a Deus, anteriores, e aqueles que dizem respeito às relações humanas, na sequência, a partir do "não matar". Esse mandamento da honra, além disso, possui duplo aspecto, social e religioso. Social, porque trata da ação de apoio aos pais idosos, pelos filhos adultos, ${ }^{16}$ a fim de manter a família com os valores que isso implica naquela sociedade. Religioso, porque prescreve para com os pais um tratamento normalmente devido a Deus, pelo uso do verbo honrar (com esta raiz hebraica kbd) (GARCIA LOPEZ, 1995, p. 54).

Serafini (2018, p. 105-111), ao aprofundar esses dados, conclui que os pais possuem participação na obra criadora de Deus, por transmitirem a vida, a Lei e os bens materiais. Wénin (1997, p. 37) amplia essa compreensão do dom da vida, transmitido pelos pais, e completa que, ao valor primordial da vida, dom gratuito que vem de Deus, acrescentam-se outros dois dons concedidos por Deus a Israel, a Lei ou instrução, dita torah, para assegurar valores e normas de convivência; e a terra, herança dos antepassados para as próximas gerações, para garantir a vida próspera e feliz. É o que expressa o texto do mandamento, sobretudo com os dois acréscimos estabelecidos pela versão do Deuteronômio, de que a honra aos pais é uma condição estabelecida por Deus para conseguir vida longa, acompanhada da promessa de felicidade na posse da terra doada por Deus.

\begin{tabular}{|l|l|}
\hline Ex 20 & Dt 5 \\
\hline${ }^{12}$ Honra teu pai e tua mãe, & ${ }^{16}$ Honra teu pai e tua mãe, \\
\hline
\end{tabular}

\footnotetext{
${ }^{16}$ Beulke (2004, p. 15-27) interpreta o "quarto mandamento" na perspectiva das pessoas idosas.
} 


\begin{tabular}{|l|l|}
\hline para que se prolonguem os teus dias & CONFORME TE ORDENOU YHWH TEU \\
DEUS, \\
para que os teus dias se prolonguem \\
E PARA QUE TUDO CORRA BEM PARA \\
na terra que Yhwh teu Deus te dá. & na terra que Yhwh teu Deus te dá. \\
\hline
\end{tabular}

“CONFORME TE ORDENOU YHWH TEU DEUS" (Dt 5,16) é o acréscimo já comentado com relação ao mandamento anterior, como citação da fórmula de promulgação divina, para expressar, aqui, a importância do respeito aos genitores, como partícipes da obra criadora de Deus.

“E PARA QUE TUDO CORRA BEM PARA TI" (Dt 5,16$)$ é outro acréscimo típico do Deuteronômio, associado à promessa do prolongamento dos dias, assim como à posse da terra. $O$ texto original explicita as duas finalidades, com a repetição do "para que" (I'ma'an), além de longos dias, Deus promete felizes dias de vida (LOZA, 1989, p. 123-124). ${ }^{17}$

A fraseologia deste preceito é tipicamente deuteronômica, tanto no que se refere ao prolongar-se de dias felizes quanto à posse da terra fértil e cultivável ('adamah). A expressão literal associando "para que tudo vá bem para ti" com longos e felizes dias na posse da terra é repetida inúmeras vezes (Dt 4,$40 ; 5,29.33 ; 6,3.18 ; 12,25.28 ; 22,7$ ). (NELSON, 2002, p. 83).

Segundo Schmidt (1996, p. 143-144), "para que tudo corra bem para ti" é um "augúrio de bênção", acrescentado pelo Deuteronômio ao primeiro augúrio, "para que teus dias se prolonguem". O autor explica ainda que essa referência à bênção se justifica, neste mandamento de pai e mãe, pela relação que a

\footnotetext{
${ }^{17}$ A expressão "vá bem para ti" (yiytab lak) é traduzida como "sejas feliz" pela Bíblia Sagrada Vozes (1982), Bíblia Tradução Ecumênica (1994) e Bíblia Sagrada CNBB (2010).
} 
paternidade e maternidade têm com o próprio dom da vida que vem de Deus. Essa ligação se expressa, formalmente, pela redação positiva do preceito.

Pela redação positiva, justamente, se dá um alargamento na compreensão do preceito, visto que as formulações mais antigas eram expressas de maneira negativa, isto é, "Quem amaldiçoar seu pai ou sua mãe será morto" (Ex 21,17; Lv 20,9) (VON RAD, 1981, p. 66). ${ }^{18}$

\section{Duas ordens para o último mandamento: não cobiçar e não desejar (Dt 5,21)}

Já estava expresso nos dois mandamentos anteriores, de maneira lapidar “Não cometerás adultério. Não roubarás" (Dt 5,18-19). Os dois últimos preceitos praticamente repetem, em paralelismo, as mesmas duas leis. Mas porque as repete e o que acrescenta? O acréscimo mais marcante, com relação aos dois mandamentos anteriores, é a relação com o próximo, tanto na redação do Êxodo quanto na do Deuteronômio. Em ambas, o "próximo" é repetido três vezes, para dizer que não se trata apenas de roubar bens materiais, mas da intenção de ferir as relações de alteridade (PAPOLA, 2011, p. 107). Esse aspecto é acentuado pelos acréscimos e mudanças inseridos pela versão deuteronomista ${ }^{19}$.

\begin{tabular}{|l|l|}
\hline Ex 20 & Dt 5 \\
\hline${ }^{17}$ Não cobiçarás a casa do teu próximo. & ${ }^{21}$ Não cobiçarás a mulher do teu \\
\hline
\end{tabular}

18 Sobre a importância histórica do mandamento da honra aos pais, veja Crüsemann (1995, p. 5055).

${ }^{19}$ A partir daí, abrem-se longas discussões. A primeira diz respeito à redação, havendo uma tendência em reconhecer que os acréscimos do Deuteronômio, com relação a esse mandamento, são posteriores (SCHÜNGEL-STRAUMANN, 1977, p. 75). A segunda se refere à tradição que distinguiu aqui dois mandamentos ao invés de um só (GARCIA LOPEZ, 1995, p. 71). Sobre as diversas interpretações do décimo mandamento, sobretudo rabínicas, veja Rofé (1990, p. 45-65). 


\begin{tabular}{|l|l|}
\hline Não cobiçarás a mulher de teu próximo, & próximo; \\
nem o seu escravo, nem a sua escrava, & nem DESÉximo, NEM O SEU CAMPO, \\
nem o seu boi, nem o seu jumento, nem & nem o seu escravo, nem a sua escrava, \\
coisa alguma que pertença a teu & nem o seu boi, nem o seu jumento, nem \\
próximo. & coisa alguma que pertença ao teu \\
& próximo. \\
\hline
\end{tabular}

"Não cobiçarás a mulher do teu próximo; nem DESEJARÁs para ti a casa do teu próximo" (Dt 5,21) estabelece alterações com relação ao preceito paralelo. Primeiramente, há uma inversão na ordem entre a casa e a mulher do próximo. Mas a mudança mais significativa se refere ao acréscimo do verbo desejar com referência aos bens, para distinguir do cobiçar referente à mulher do próximo.

O Deuteronômio priorizou a posição da mulher, antes dos bens materiais e com um verbo que a distingue explicitamente de todas as demais posses. Essas modificações, evidentemente, não são casuais, mas guardam intenções de quem escreveu. O lugar da mulher no vértice indica que "a sua posição social aparece mudada" (SCHÜNGEL-STRAUMANN, 1977, p. 73).

O verbo que interdita cobiçar ( $\underline{h} m$ d) a mulher do próximo significa cobiçar e tomar, contendo, portanto, dupla dimensão, seja a emoção que move a intenção secreta, seja a ação que leva à apropriação indevida. Esse duplo significado está explícito em outros usos do mesmo verbo, como na recomendação em não cobiçar e não se apropriar da prata e do ouro que recobrem os ídolos (Dt 7,25). Mais claramente, ilustra a recomendação de 
Miquéias (Mq 2,2): "Se cobiçam campos, eles os roubam, se casas, eles as tomam" (GARCIA LOPEZ, 1995, p. 71; VON RAD, 1981, p. 67) ${ }^{20}$.

Já o verbo desejar ('wh no hitpael), acrescentado pelo Deuteronômio, parece manter a tendência à interiorização dos atos, incluindo a intenção de maquinar e o ato de apoderar-se dos bens do próximo (SCHMIDT, 1996, p. 190).

"NEM O SEU CAMPO" (Dt 5,21) é o acréscimo feito em paralelo com a casa e em posição posterior à mesma. Casa e campo formam o par que designa a propriedade como um todo. A norma do Deuteronômio estaria já num tempo pós exílico, quando o direito à herança nahalah) já não estava mais vigente (SCHÜNGEL-STRAUMANN, 1977, p. 75). ${ }^{21}$

\section{Para concluir}

A conclusão que se impõe, para um estudo como este, sobre modificações e acréscimos no texto do decálogo, é que o texto bíblico foi alterado com liberdade, de acordo com novos contextos vivenciais. Por tratar-se de um texto fundamental, contendo as palavras normativas de Deus para o seu povo, as mudanças tornam-se ainda mais surpreendentes. Mas não exclusivas, pois o mesmo se passa com outros textos bíblicos fundamentais, como as duas versões da criação, no início da Bíblia ou as duas versões da infância de Jesus, no começo do Novo Testamento. Os exemplos poderiam se multiplicar, como em relação às duas versões do pai-nosso, das bem-aventuranças ou das palavras sobre a ceia, para ficar apenas em três textos essenciais do Novo Testamento. Isso apontaria para uma leitura da Bíblia inserida no contexto original de cada texto, bem como para uma hermenêutica sempre atual dessas mesmas palavras. Para além de fundamentalismos dogmáticos, a palavra convida à constante renovação. Nessa mesma perspectiva, por certo, o texto do decálogo se

\footnotetext{
${ }^{20}$ Kessler (2015, p. 53) analisa a cobiça à mulher, nesse décimo mandamento, à luz da legislação relativa a débitos e afirma: "Assim, o mandamento do Decálogo não 'cobiçarás a mulher do teu próximo' não tem nada a ver com relações sexuais. Ele proíbe o desejo de tomar a mulher do próximo como escrava na própria casa".

${ }^{21}$ Sobre o contexto histórico desse mandamento, veja Crüsemann (1995, p. 64-67).
} 
denomina, originalmente, "palavras", e não "mandamentos", em sentido estrito.

Reconhecida como palavra de Deus, a Bíblia não deixa de se identificar como palavra humana. E como palavra plenamente humana, permite adequações aos diversos contextos históricos em que ela ressoa. A Dei Verbum (n. 2) exprime essa condescendência divina ao afirmar: "Em virtude dessa revelação, Deus invisível (cf. $\mathrm{Cl}$ 1,15; $1 \mathrm{Tm}$ 1,17), na riqueza do seu amor, fala aos homens como a amigos (cf. Ex 33,11; Jo 15,14-15) e conversa com eles (cf. Br 3,38)...".

\section{Referências}

BEAUCHAMP, P. La legge di Dio. Asti: Piemme, 2000.

BEULKE, G. O Quarto Mandamento e seu desafio para filhos e filhas. Estudos Bíblicos, Petrópolis, v. 82, p. 15-27, 2004.

BíBLIA de Jerusalém (A). São Paulo: Paulus, 2002.

BíBLIA Sagrada CNBB. Brasília: CNBB, 2010.

BÍBLIA Sagrada Vozes. Petrópolis: Vozes, 1982.

BÍBLIA Tradução Ecumênica (TEB). São Paulo: Loyola, 1994.

BLEVINS, K. Observing Sabbath. Review and Expositor, v. 113, n. 4, p. 478-487, 2016.

CARRIÈRE, J.-M. O livro do Deuteronômio: escolher a vida. São Paulo: Loyola, 2005.

CRÜSEMANN, F. Preservação da liberdade: o decálogo numa perspectiva históricosocial. São Leopoldo: Sinodal, 1995.

Dei Verbum. São Paulo: Paulinas, 1966.

GARCIA LOPEZ, F. O decálogo. São Paulo: Paulus, 1995. (Cadernos bíblicos, 65).

GARCÍA LÓPEZ, F. Analyse littéraire de Deutéronome, V-XI. Revue Biblique, Paris, v. 84, p. 481-522, 1977.

GERSTENBERGER, E. Os dez e os outros mandamentos de Deus. Estudos Bíblicos, Petrópolis, v. 51, p. 8-22, 1996. 
HARRELSON, W. J. Os dez mandamentos e os direitos humanos. São Paulo: Paulinas, 1987. (Coleção temas bíblicos).

HOSSFELD, F.-L. Der Dekalog: Seine späten Fassungen, die originale Komposition und seine Vorstufen. Göttingen: Vandenhoeck, 1982. (OBO, 45).

KESSLER, R. Debt and the Decalogue: The Tenth Commandment. Vetus Testamentum, v. 65, p. 53-61, 2015.

KLINGBEIL, G. A. The Sabbath Law in the Decalogue(s): Creation and Liberation as a Paradigm for Community. Revue Biblique, Paris, p. 491-509, 2010.

LEVIN, C. Der Dekalog am Sinai. Vetus Testamentum, v. 35, p. 165-191, 1985.

LOZA, J. Las Palabras de Yahvé: Estudio del Decálogo. México: Universidad Pontificia, 1989.

MARKL, D. The Decalogue and its Cultural Influence. Sheffield: Sheffield Phoenix Press, 2017.

MAYES, A. H. Deuteronomy 5 and the Decalogue. Proceedings of the Irish Biblical Association, v. 4, p. 68-83, 1980.

MESTERS, C. Bíblia, livro da aliança - Ex 19-24. São Paulo: Paulinas, 1986.

MEYNET, R. I due decaloghi, legge di libertà (Es 20,2-17 \& Dt 5,6-21). Gregorianum, Roma, v. 81, n. 4, p. 659-692, 2000.

NELSON, R. D. Deuteronomy. Louisville: Westminster John Knox Press, 2002. (The Old Testament Library).

OLIVEIRA, B. C. de. O Decálogo: Palavras de uma aliança. Estudos Bíblicos, Petrópolis, v. 9, p.11-23, 1987.

PAPOLA, G. Deuteronomio: introduzione, traduzione e commento. Milano: San Paolo, 2011.

REIMER, H.; REIMER, I. R. Tempos de graça: o jubileu e as tradições jubilares na Bíblia. São Leopoldo: CEBI; Sinodal; Paulus, 1999.

ROFÉ, A. The Tenth Commandment in the Light of Four Deuteronomic Laws. In: SCHMIDT, Werner H. I dieci comandamenti e l'etica veterotestamentaria. Brescia: Paideia, 1996. (Studi Biblici, 114).

SCHÜNGEL-STRAUMANN, H. Decalogo e comandamenti di Dio. Brescia: Paideia, 1977. (Studi Biblici, 42). 
SEGAL, B.-Z. (Ed.). The Ten Commandments in History and Tradition. Jerusalem: The Magnes Press, The Hebrew University, 1990. p. 45-65.

SERAFINI, F. Accogliere la libertà, condividere la vita: commento esegetico e teologico al Decalogo. Milano: San Paolo, 2018.

SILVA, J. A. da. Leis de vida e leis de morte. Os dez mandamentos e seu contexto social. Estudos Bíblicos, Petrópolis, v. 9, p. 38-51, 1986.

SILVA, V. da. Deus ouve o clamor do povo: teologia do êxodo. São Paulo: Paulinas, 2004.

SIQUEIRA, T. M. A Torá à luz do Decálogo (Mandamentos teológicos e éticos). International Studies on Law and Education, 21 set-dez 2015. CEMOrOc-Feusp / IJI-Univ. do Porto. Disponível em: <http://www.hottopos.com/isle21/99-112Tercio.pdf>. Acesso em: 20 mar. 2019.

VON RAD, G. Deuteronomio. Brescia: Paideia, 1981.

WÉNIN, A. Le décalogue: approche contextuelle, théologie et anthropologie. In: FOCANT, C. (Dir.). La loi dans l'un et l'autre testament. Paris: Cerf, 1997. p. 9-43. (Letio Divina, 168).

RECEBIDO: $19 / 04 / 2019$

RECEIVED: 04/19/2019

APROVADO: $27 / 06 / 2019$

APPROVED: 06/27/2018 